University of Nebraska - Lincoln

DigitalCommons@University of Nebraska - Lincoln

USGS Staff - Published Research

US Geological Survey

1985

\title{
Well Bore Breakouts and in Situ Stress
}

Mark D. Zoback

Stanford University, zoback@stanford.edu

Daniel Moos

Columbia University

Larry Mastin

Stanford University

Roger N. Anderson

Columbia University, anderson@ldeo.columbia.edu

Follow this and additional works at: https://digitalcommons.unl.edu/usgsstaffpub

Part of the Earth Sciences Commons

Zoback, Mark D.; Moos, Daniel; Mastin, Larry; and Anderson, Roger N., "Well Bore Breakouts and in Situ Stress" (1985). USGS Staff -- Published Research. 458.

https://digitalcommons.unl.edu/usgsstaffpub/458

This Article is brought to you for free and open access by the US Geological Survey at DigitalCommons@University of Nebraska - Lincoln. It has been accepted for inclusion in USGS Staff -- Published Research by an authorized administrator of DigitalCommons@University of Nebraska - Lincoln. 


\title{
Well Bore Breakouts and in Situ Stress
}

\author{
Mark D. Zoback, ${ }^{1}$ Daniel Moos, ${ }^{2,3}$ ANd Larry Mastin ${ }^{4}$ \\ U.S. Geological Survey, Menlo Park, California
}

ROGER N. ANDERSON

Lamont-Doherty Geological Observatory of Columbia University, Palisades, New York

\begin{abstract}
The detailed cross-sectional shape of stress induced well bore breakouts has been studied using specially processed ultrasonic borehole televiewer data. We show breakout shapes for a variety of rock types and introduce a simple elastic failure model which explains many features of the observations. Both the observations and calculations indicate that the breakouts define relatively broad and flat curvilinear surfaces which enlarge the borehole in the direction of minimum horizontal compression. This work supports the hypothesis that breakouts result from shear failure of the rock where the compressive stress concentration around the well bore is greatest and that breakouts can be used to determine the orientation of the horizontal principal stresses in situ.
\end{abstract}

\section{INTRODUCTION}

Data from commercially available four-arm caliper logs have enabled several workers to show that there are spalled sections of well bores, termed "breakouts" in the petroleum industry, in which the average azimuth of the long (or spalled) dimension is very consistent within a given well or oil field [Cox, 1970; Babcock, 1978; Schafer, 1980; Brown et al., 1980]. Bell and Gough [1979] and other workers [Springer and Thorpe, 1981; Gough and Bell, 1981, 1982; Plumb, 1982; Healy et al., 1982; Hickman et al., 1982; Blumling et al., 1983; Cox, 1983] have suggested that the consistent azimuth of the long dimension of the hole was parallel to the azimuth of the least horizontal principal stress.

In this paper we present detailed measurements of the crosssectional shape of breakouts in several wells using specially processed data from an ultrasonic borehole televiewer and extend the theoretical analysis of the mechanism of breakout formation proposed by Bell and Gough [1979, 1982] and Gough and Bell [1981, 1982] in order to explain better the observed breakout shapes. One of the case histories examined in this paper, a well located at Auburn, New York, is discussed at length by Hickman et al. [this issue].

\section{ObServations of Breakouts}

The analysis of breakout formation by Gough and Bell [1981] and Bell and Gough [1982] predicted that breakouts are spalled regions on each side of the well bore which are centered at the azimuth of the least horizontal principal stress $S_{h}$ where the compressive stress concentration was greatest. They suggested that the breakouts were the result of localized compressive shear failure, and their analysis predicted that the region of failure would be triangular in cross section, enclosed

\footnotetext{
${ }^{1}$ Now at Department of Geophysics, Stanford University, California. nia.

${ }^{2}$ Also at Department of Geophysics, Stanford University, Califor-

${ }^{3}$ Now at Lamont-Doherty Geological Observatory of Columbia University, Palisades, New York.

${ }^{4}$ Also at Department of Applied Earth Sciences, Stanford University, California.
}

Copyright 1985 by the American Geophysical Union.

Paper number 4B1300.

0148-0227/85/004B-1300\$05.00 by flat conjugate shear planes oriented at a constant angle to the azimuth of the far-field horizontal principal stresses. In other words, the breakouts would have the appearance of pointed "dog ears" on opposite sides of the hole. However, as their primary source of information about well bore breakouts was four-arm caliper logs, their theory could not be tested because these instruments yield only two orthogonal well bore diameters as a function of depth and no information is avaiable on the detailed shape of the breakouts.

To overcome the limitations of four-arm caliper data, we have analyzed the detailed shape of breakouts in a variety of rock types using data from an ultrasonic borehole televiewer (Zemanek et al. [1970] describe the operation of the televiewer in detail). The televiewer is a well-logging tool that consists of a magnetically oriented rotating piezoelectric transducer which emits and receives an ultrasonic $(\sim 1 \mathrm{MHz})$ acoustic pulse that is reflected from the borehole wall 600 times per revolution. In typical applications of the televiewer, well bore reflectivity, or "smoothness," is plotted as a function of azimuth and depth by displaying the amplitude of the reflected pulse as brightness on a three-axis oscilloscope. This yields an "unwrapped" image of the well bore surface. The televiewer has previously been very effective for studying fractures which intersect well bores at depth [e.g., Seeburger and Zoback, 1982]. In many cases, breakouts are also discernible on televiewer photos as regions of low reflectivity. By analysis of the travel time of the acoustic pulse as a function of azimuth, we have been able to make detailed cross sections of the well bore in intervals where breakouts occur. Conversion of travel time to borehole size is straightforward since the diameter of the hole is accurately known from caliper measurements.

Figure 1 shows breakout data from a well near Auburn, New York, which are described in detail by Hickman et al. [this issue]. Figure $1 a$ shows a reflectivity televiewer record of a 6.5-m-long zone of breakouts in the well, and Figure $1 b$ shows a cross-sectional view of the borehole at a depth of $1476.3 \mathrm{~m}$. Note that the breakouts are basically broad and flat depressions and do not have the pointed "dog ear" character predicted by the Gough and Bell [1981] theory. Although the breakouts shown in Figure $1 b$ are not symmetrical and exactly $180^{\circ}$ apart, the mean breakout direction in the well is within a few degrees of the direction of least horizontal compression determined by hydraulic fracturing in the same well (Figure 1c). 


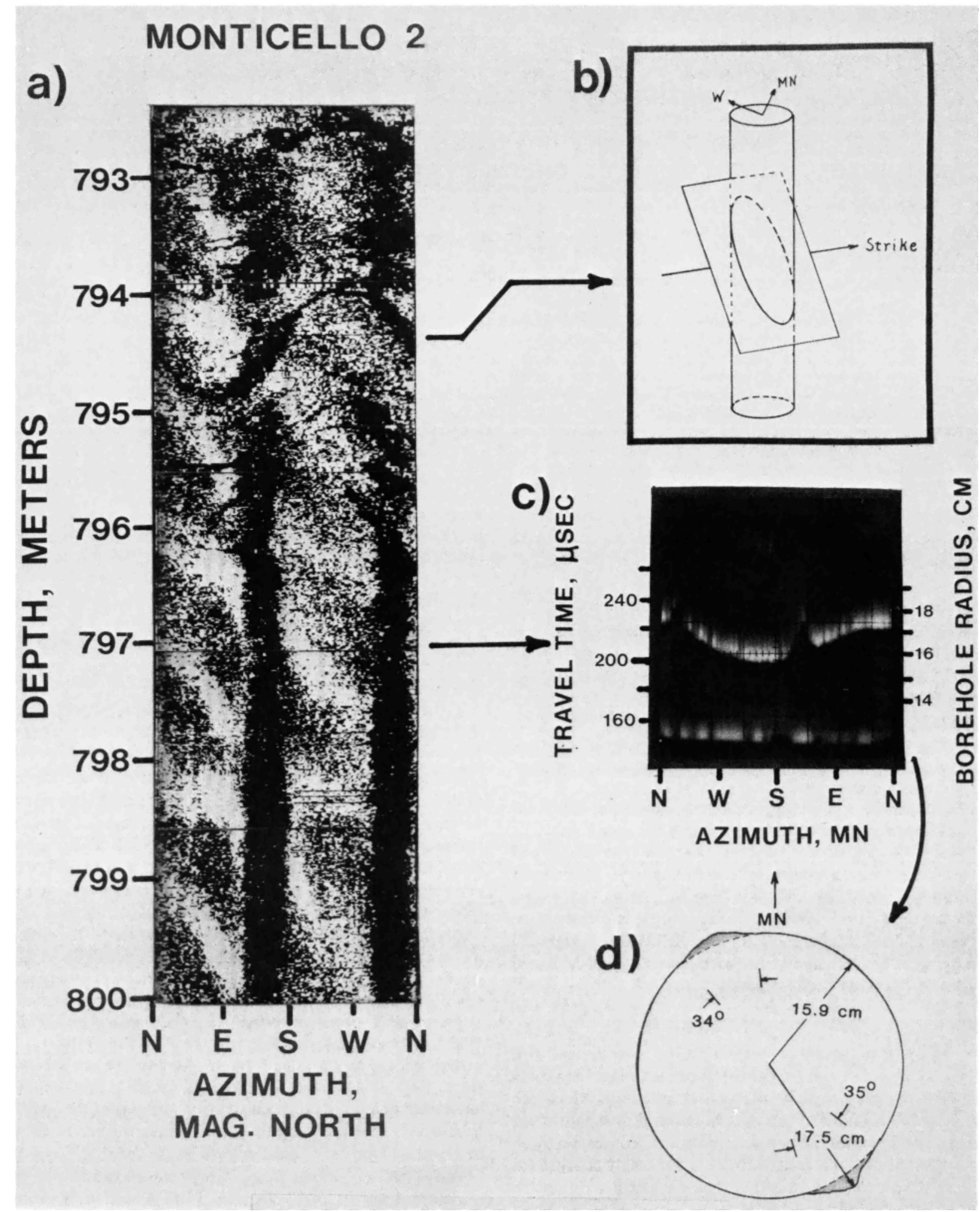

Fig. 1. (a) Typical reflectivity borehole televiewer record of a $7.5-\mathrm{m}$ section of a well drilled in granitic rock at Monticello, South Carolina. The sinusoidal dark (low reflectivity) bond on the televiewer record centered at $794.5 \mathrm{~m}$ is due to a fracture plane intersecting the borehole as illustrated in Figure $1 b$. The vertical dark bonds centered approximately $180^{\circ}$ apart correspond to low-amplitude reflections coming from breakouts shown in Figure 1d. (b) A fracture plane intersecting a borehole produces a sinusoidal dark bond on the reflectivity record. (c) A photograph of an oscilloscope record showing how travel time as a function of azimuth is determined for a single rotation of the acoustic transducer at a depth of about $797 \mathrm{~m}$. Six hundred reflected acoustic pulses (one rotation of the transducer) are displayed side by side as a function of azimuth with the amplitude of the reflection modulating scope intensity. The reflected pulse initially has a negative polarity. The large sinusoidal variation in travel time as a function of azimuth corresponds to the televiewer not being perfectly centered in the hole. the two sharp travel time delays just west of north and east of south are associated with breakouts. The borehole radius which corresponds to travel time is shown on the right. Note that the absissa is labeled in the reverse manner of Figure $1 a$, but in both figures the breakouts are west of north and east of south. (d) Borehole shape corresponding to data shown in Figure $1 c$. The breakouts are approximately $35^{\circ}$ wide and enlarge the radius of the hole by about $15 \mathrm{~mm}$. 


\section{AUBURN, NEW YORK}
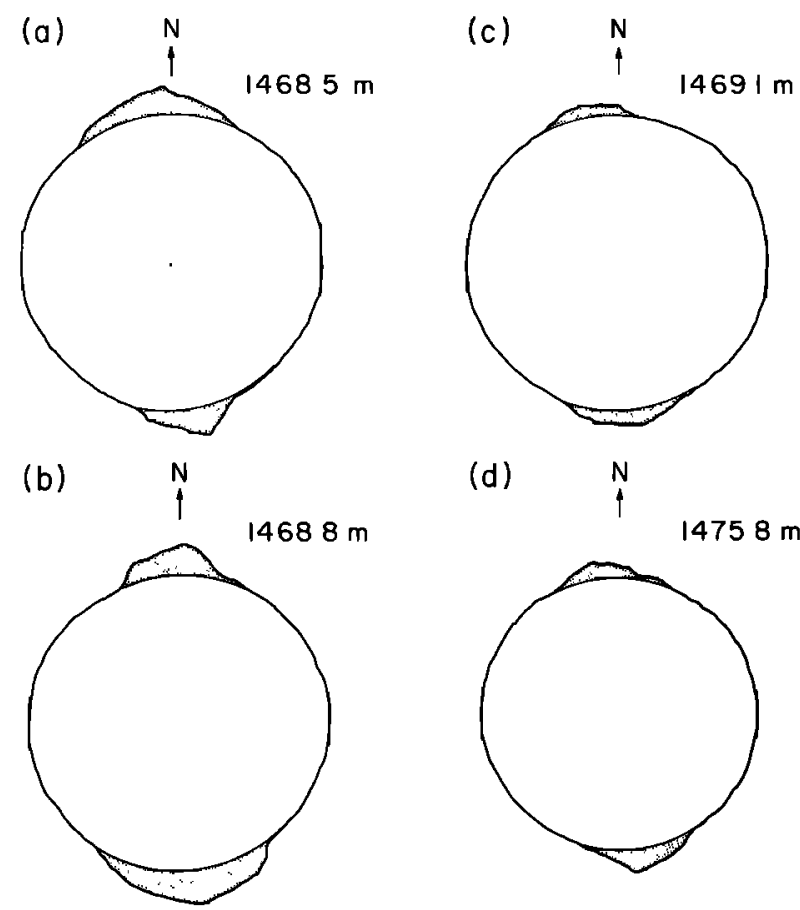

(d)

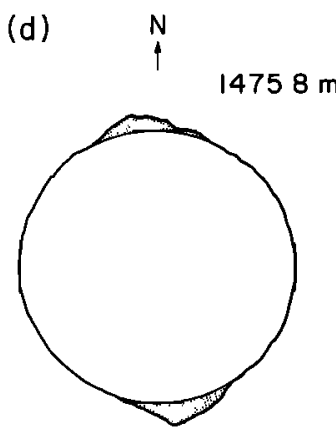

Fig. 2. Representative breakout shapes in the Auburn, New York, well. The breakout shown in Figure $2 d$ is part of that shown in Figure 1a. The shaded area represents the difference between the observed well bore shape and the nominal well bore diameter.

Figure 2 shows breakouts in Paleozoic sandstone at other depths in the Auburn well, and Figures 3 and 4 show breakouts observed in granitic rocks and tuff, respectively. Figure $2 c$ shows broad, flat-bottomed breakouts in the Auburn well which are similar to those shown in Figure 1. However, deeper

\section{MONTICELLO 2}

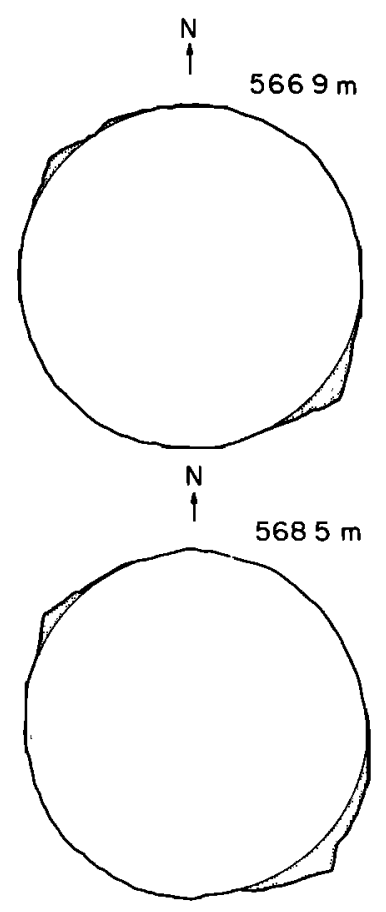

Fig. 3. Representative breakout shapes in granite from the Monticello 2 well near Monticello, South Carolina.

\section{NEVADA TEST SITE}
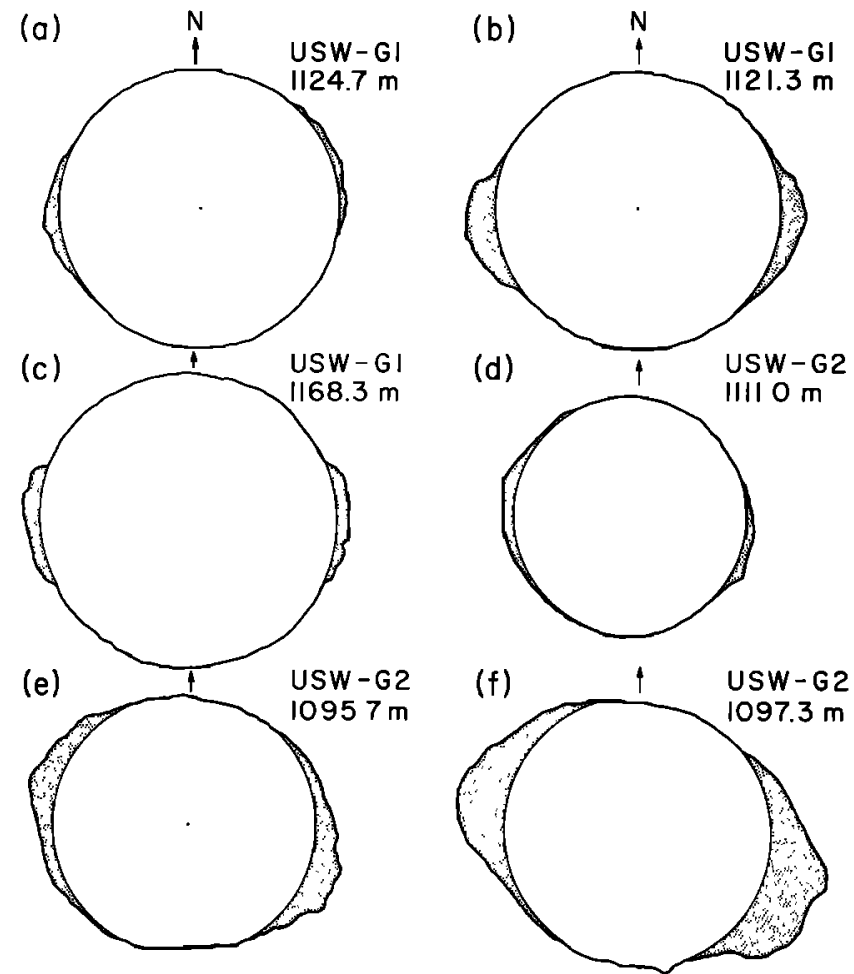

Fig. 4. Representative breakout shapes in tuff from wells drilled at the Nevada Test Site. $(a)-(c)$ Well USW-G1, where the breakouts are concentrated in a flow breccia unit. $(d)-(f)$ Well USW-G2, where the breakouts are in the Bullfrog (Figure $4 d$ ) and Trom (Figure $4 c$ ); Figure $4 f$ is units of the Crater Flat Tuff.

breakouts are also present in the well (Figures $2 a$ and $2 b$ ). Figure 3 shows breakouts in wells drilled in granitic rock. Although the breakouts are somewhat irregular in the wells, they are basically broad and flat-bottomed, as in Figure $2 c$. Figure 4 shows breakouts in two wells drilled in tuff at the Nevada Test Site. In these wells the breakout shapes vary considerably and range from being broad and flat-bottomed (Figures $4 a$ and $4 d$ ) to being relatively deep. Note, however,
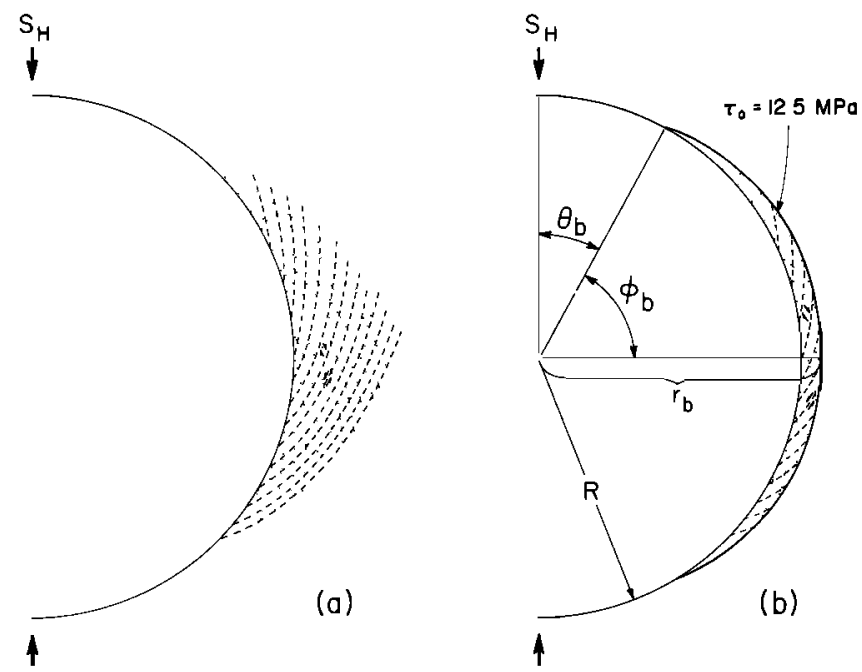

Fig. 5. (a) Orientation of potential shear failure surfaces adjacent to a well bore for $S_{H}{ }^{*}=45 \mathrm{MPa}, S_{h}{ }^{*}=30 \mathrm{MPa}, \Delta P=0$, and $\mu=1.0$. (b) Area in which failure is expected for $\tau_{0}=12.5 \mathrm{MPa}$. The $\theta_{b}, \phi_{b}$, and $r_{b}$ are described in the text. 


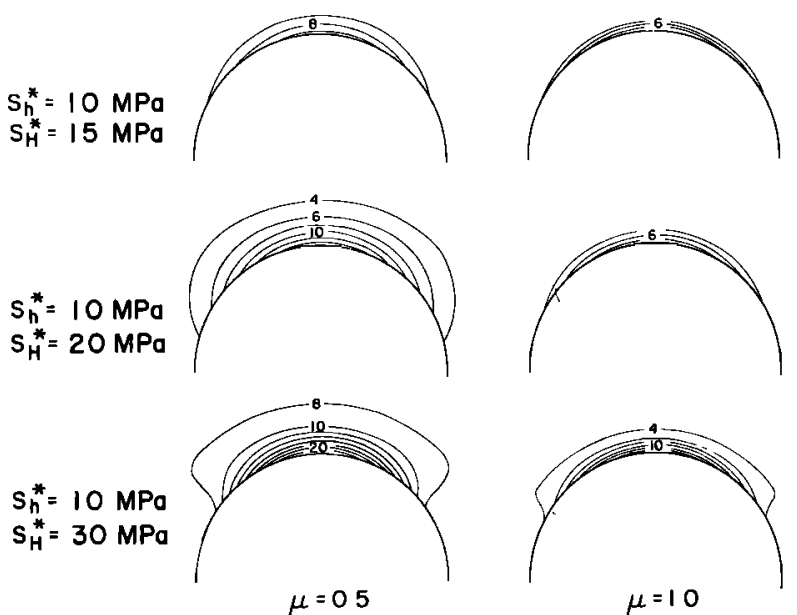

Fig. 6. Theoretical size of the areas in which the compressive shear strength of the rock is exceeded by the concentrated stresses. For the values of the effective compressive principal stress and coefficient of friction shown, the contours in each figure define the size of the initial failure zone for a given value of $\tau_{0}$ and $\Delta P=0$.

that the deep breakouts are not appreciably wider than the more shallow breakouts.

Independent evidence in each of the cases presented in Figures 1-4 shows that the breakouts are aligned with the local direction of least horizontal compression. Hickman et al. [this issue] show that the Auburn breakouts are perpendicular to hydraulic fracture orientations in the same well; Stock et al. [1983] discuss similar evidence for the wells on the Nevada Test Site; S. H. Hickman and M. D. Zoback (written communication, 1984) show that the Monticello breakouts indicate a direction of maximum horizontal compression which is about the mean of $p$ axis of local earthquakes. In each of these cases the breakouts are observed to form in the region around the hole of greatest compressive stress, as predicted by Gough and Bell [1981]. However, the examples suggest that many breakouts can be rather broad and flat-bottomed, unlike the "dog ear" shape predicted by their theory. To investigate this, we consider below a simple theoretical model for breakout initiation that considers the nature of the concentrated stress field around the hole in more detail than Gough and Bell [1981].

\section{BrEAKOUT INITIATION}

For a cylindrical hole in a thick, homogeneous, isotropic elastic plate subjected to effective minimum and maximum principal stresses $\left(S_{h}{ }^{*}\right.$ and $\left.S_{H}{ }^{*}\right)$, the following equations apply [Kirsch, 1898; Jaeger, 1961]:

$$
\begin{aligned}
& \sigma_{r}=\frac{1}{2}\left(S_{H}{ }^{*}+S_{h}{ }^{*}\right)\left(1-\frac{R^{2}}{r^{2}}\right)+\frac{1}{2}\left(S_{H}{ }^{*}-S_{h}{ }^{*}\right) \\
& \cdot\left(1-4 \frac{R^{2}}{r^{2}}+3 \frac{R^{4}}{r^{4}}\right) \cos 2 \theta+\frac{\Delta P R^{2}}{r^{2}} \\
& \sigma_{\theta}=\frac{1}{2}\left(S_{H}{ }^{*}+S_{h}{ }^{*}\right)\left(1+\frac{R^{2}}{r^{2}}\right)-\frac{1}{2}\left(S_{H}{ }^{*}-S_{h}{ }^{*}\right) \\
& \left.\tau_{r \theta}=-\frac{1}{2}\left(S_{H}{ }^{*}+S_{h}{ }^{*}\right)\left(1+\frac{R^{4}}{r^{4}}\right) \cos 2 \theta-\frac{\Delta P R^{2}}{r^{2}}-3 \frac{R^{4}}{r^{4}}\right) \sin 2 \theta
\end{aligned}
$$

where $\sigma_{r}$ is the radial stress, $\sigma_{\theta}$ is the circumferential stress, $\tau_{r \theta}$ is the tangential shear stress, $R$ is the radius of the hole, $r$ is distance from the center of the hole, $\theta$ is azimuth measured from the direction of $S_{H}^{*}$, and $\Delta P$ is the difference between the fluid pressure in the borehole and that in the formation (positive indicates excess pressure in the borehole). The conjugate surfaces along which compressive shear failure would be expected to occur are shown in Figure $5 a$ for nominal stress values of $S_{H}{ }^{*}=45 \mathrm{MPa}$ and $S_{h}^{*}=30 \mathrm{MPa}$. Away from the well bore, these conjugate shear failure surfaces are planes oriented at an angle to $S_{H}{ }^{*}$ controlled by the coefficient of friction (in this case assumed to be 1.0). Near the well bore the stress concentration results in markedly curved potential shear failure surfaces. This is the result of rotation of the azimuths of the maximum and minimum principal stresses near the free surface of the cylindrical well bore. It is important to note that the magnitude of shear and effective normal stress along these potential failure surfaces varies as a function of $r$ and $\theta$. The region where compressive shear failure is expected to occur can be predicted from the extended Griffith criterion of $M c$ Clintock and Walsh [1962]. This criterion considers the extension of closed cracks which have a finite frictional strength in a biaxial stress field. In this context, potential failure surfaces are cracks with a frictional sliding coefficient of $\mu$, subjected to a shear stress and effective normal stress. As discussed by Paterson [1978] and Jaeger and Cook [1979], the McClintock and Walsh [1962] analysis is equivalent to the Coulomb criterion in which the failure envelope has a slope equal to the coefficient of frictional sliding, $\mu$, and an intercept $\tau_{0}$ equal to the cohesive strength of the rock. The region around the well bore in which failure is expected can then be computed in terms of a simple Mohr's circle. Failure will occur where the radius of the Mohr circle $\left\{\left[\left(\sigma_{\theta}-\sigma_{r}\right) / 2\right]^{2}+\tau_{r \theta}{ }^{2}\right\}^{1 / 2}$ is greater than or equal to the distance from the center of the circle to the failure line given by $\left[\mu /\left(1+\mu^{2}\right)^{1 / 2}\right]\left\{\sigma_{\theta}+\left[\left(\sigma_{\theta}+\sigma_{r}\right) / 2\right]\right\}$. To compute the size and shape of the region around the well bore that is expected to fail under given in situ stresses, we can rearrange the above expressions. Assuming that the NavierCoulomb criterion $\sigma_{r}=\tau_{0}-\mu \sigma_{\theta}$ applies, the maximum value of cohesive strength at which the material will fail is given by

$$
\tau_{0}=\left(1+\mu^{2}\right)^{1 / 2}\left[\left(\frac{\sigma_{\theta}-\sigma_{r}}{2}\right)^{2}+\tau_{r \theta}^{2}\right]^{1 / 2}-\mu\left(\frac{\sigma_{\theta}+\sigma_{r}}{2}\right)
$$

We have chosen to isolate the variable $\tau_{0}$ because where $\mu$ for most rocks varies between 0.6 and 1.0 [Byerlee, 1978], $\tau_{0}$ can vary from several megapascals to a few tens of megapascals [Handin, 1966]. By substituting appropriate values into (1)(4), we can predict the size of initial region in which the ratio of shear to normal stress on the potential shear surfaces is large enough to cause failure. For $\Delta P=0$ and a nominal value of $\tau_{0}=12.5 \mathrm{MPa}$, Figure $5 b$ shows the size of the region in which the stresses exceed the rock strength on the failure surfaces shown in Figure $5 a$.

Figure 6 shows several other examples for different stress values and coefficients of friction. As in Figure $5 b$, the contours shown in Figure 6 are envelopes enclosing the region in which the ratio of shear to normal stress is large enough to cause failure for the given value of $\tau_{0}$ and $\Delta P=0$. Figure 6 illustrates that the breakout shapes are generally broad and flat-bottomed. For given values of $S_{h}{ }^{*}, S_{H}{ }^{*}$, and $\mu$ the lower the cohesive strength of the rock, the deeper and wider the breakout region. For example, in the case where $S_{h}{ }^{*}=10$ $\mathrm{MPa}, S_{H}{ }^{*}=15 \mathrm{MPa}$, and $\mu=0.5$, no breakout would be observed in a borehole drilled in rock with a cohesive strength higher than $10 \mathrm{MPa}$. However, if the cohesive strength were much lower than $6 \mathrm{MPa}$, the breakouts would be so large as to extend nearly around the borehole. We have not shown 


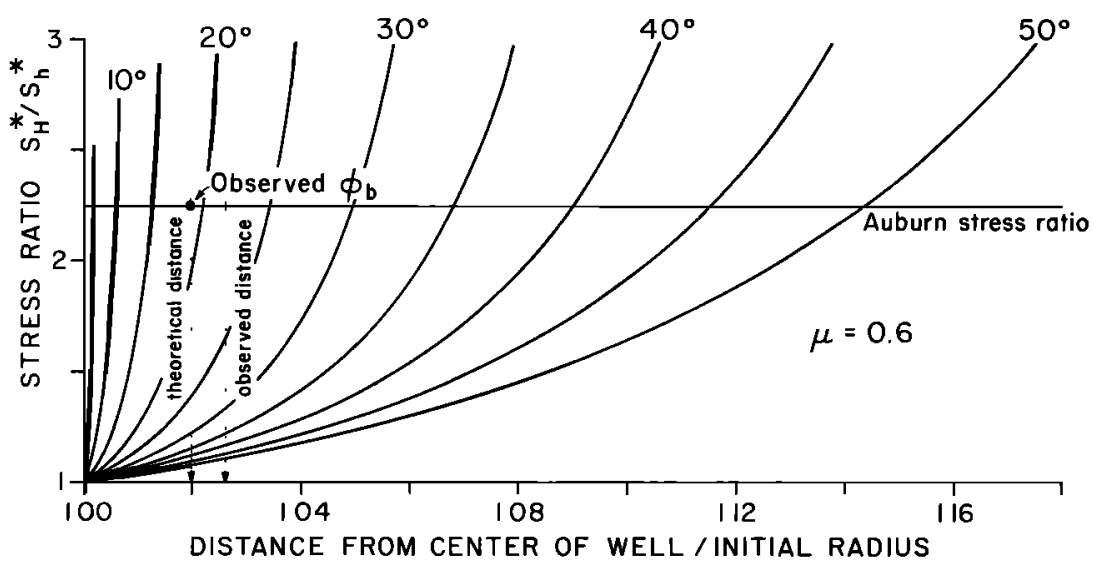

Fig. 7. Relationship between the ratio of the horizontal principal stresses and the maximum depth and width of breakouts. The curves correspond to breakouts with various values of $\phi_{b}$, the half width, where $\mu=0.6$ and $\Delta P=0$. The example data from Auburn, New York, are explained in the text.

breakout sizes for lower values of $\tau_{0}$ in Figure 6 because they would be so large as to encompass nearly the entire well and invalidate the analysis. The effects of nonzero values of $\Delta P$ are considered below.

It can be seen in Figure 6 that the effect of increasing the ratio of the horizontal principal stresses is to make the breakouts much larger for a given value of $\mu$ and $\tau_{0}$. Similarly, for a given stress ratio and $\tau_{0}$, much smaller breakouts result for larger values of $\mu$, especially for the larger stress ratios. One interesting feature in the case of the $3: 1$ stress ratio is the change in shape of large breakouts. These breakouts have distinctly steeper edges than either the deep breakouts at smaller stress ratios or the smaller breakouts at the same stress ratio. These shapes are similar to the breakout shown in Figure $4 b$. In general, the edges of the breakouts steepen as the stress ratio increases.

The broad, flat-bottomed breakouts modeled in Figure 6 are more similar to many of the breakouts shown in Figures 1-4 than the idealized "dog ears" suggested by the Bell and Gough analysis. It should be pointed out, however, that the analysis presented so far considers only the formation of a breakout in an initially cylindrical borehole. A possible explanation of the deeper, irregularly shaped breakouts shown in Figures $2-4$ is that the breakouts continue growing after their initial formation. This will be discussed in the next section.

It is straightforward to extend the theory presented above to consider the general problem of the initial size of breakouts in terms of the rocks' cohesive strength and coefficient of friction and the magnitude of the horizontal principal stresses. For simplicity, we assume here that $S_{H}{ }^{*} \leq 3 S_{h}{ }^{*}$, which is almost always the case in situ [see Brace and Kohlstedt, 1980], and that there is no excess fluid pressure in the well bore $(\Delta \mathrm{P}=0)$. A more complete analysis is presented in the appen-

TABLE 1. Comparison of Observed and Theoretical Breakout Size Auburn, New York

\begin{tabular}{cccccccc}
\hline & \multicolumn{3}{c}{ Observed } & & \multicolumn{3}{c}{ Theoretical } \\
\cline { 2 - 4 } \cline { 6 - 8 } $\begin{array}{c}\text { Depth, } \\
\text { m }\end{array}$ & $\phi_{b}$ & $r_{b} / R$ & $\begin{array}{c}r_{b}, \\
\mathrm{~mm}\end{array}$ & & $r_{b} / R$ & $\begin{array}{c}r_{b}, \\
\mathrm{~mm}\end{array}$ & $\begin{array}{c}\Delta r_{b}, \\
\mathrm{~mm}\end{array}$ \\
\hline 1471.9 & $19^{\circ}$ & 1.027 & 115.0 & & 1.019 & 114.1 & 0.9 \\
1473.1 & $20^{\circ}$ & 1.063 & 119.1 & & 1.022 & 114.5 & 4.6 \\
1474.6 & $22^{\circ}$ & 1.071 & 120.0 & & 1.027 & 115.0 & 5.0 \\
1476.3 & $15^{\circ}$ & 1.027 & 115.0 & & 1.012 & 113.3 & 1.7 \\
1476.3 & $22^{\circ}$ & 1.045 & 117.0 & 1.027 & 115.0 & 2.0 \\
\hline
\end{tabular}

dix. By substituting (1) (3) into (4), we can express the cohesive strength at the point the breakout intersects the well bore $\tau_{0}\left(R, \theta_{b}\right)$, and the cohesive strength at the breakout's deepest point, $\tau_{0}\left(r_{b}, \pi / 2\right)$, as

$$
\begin{gathered}
\tau_{0}\left(R, \theta_{B}\right)=\frac{1}{2}\left(a S_{H}{ }^{*}+b S_{h}{ }^{*}\right) \\
\tau_{o}\left(r_{b}, \pi / 2\right)=\frac{1}{2}\left(c S_{H}{ }^{*}+d S_{h}{ }^{*}\right)
\end{gathered}
$$

where

$$
\begin{gathered}
a=\left[\left(1+\mu^{2}\right)^{1 / 2}-\mu\right]\left(1-2 \cos 2 \theta_{B}\right) \\
b=\left[\left(1+\mu^{2}\right)^{1 / 2}-\mu\right]\left(1+2 \cos 2 \theta_{B}\right) \\
c=-\mu+\left(1+\mu^{2}\right)^{1 / 2}-\frac{R^{2}}{r_{b}{ }^{2}}\left[\left(1+\mu^{2}\right)^{1 / 2}-2 \mu\right] \\
+\frac{3 R^{4}}{r_{b}{ }^{4}}\left(1+\mu^{2}\right)^{1 / 2} \\
d=-\mu-\left(1+\mu^{2}\right)^{1 / 2}+\frac{3 R^{2}}{r_{b}{ }^{2}}\left[\left(1+\mu^{2}\right)^{1 / 2}+2 \mu\right] \\
-\frac{3 R^{4}}{r_{b}{ }^{4}}\left(1+\mu^{2}\right)^{1 / 2}
\end{gathered}
$$

If we assume that a breakout follows a trajectory along a given value of $\tau_{0}$ as shown in Figure 6, then

$$
\tau_{0}\left(R, \theta_{b}\right)=\tau_{0}\left(r_{b}, \pi / 2\right)
$$

It follows that

$$
\begin{gathered}
S_{h}{ }^{*}=2 \tau_{0}\left(\frac{a-c}{a d-b c}\right) \\
S_{H}{ }^{*}=2 \tau_{0}\left(\frac{d-b}{a d-b c}\right) \\
\frac{S_{H}{ }^{*}}{S_{h}{ }^{*}}=\left(\frac{d-b}{a-c}\right)
\end{gathered}
$$

Figure 7 graphically shows $S_{H}{ }^{*} / S_{h}{ }^{*}$, which is independent of $\tau_{0}$, as a function of $r_{b} / R$ and $\phi_{b}$ (where $\phi_{b}=\pi / 2-\theta_{b}$, see Figure $5 b$ ) for $\mu=0.6$. As expected, extremely little spalling will occur when the two effective horizontal stresses are about equal. Although the breakouts get deeper and wider as $S_{H}{ }^{*} / S_{h}{ }^{*}$ increases, even for large stress ratios, the well bore radius increases by only about $15 \%$ when $\phi_{b}$ is as large as $50^{\circ}$. It is clear, then, that although this simple theory of the initial formation of a breakout can explain the broad, flat-bottomed 
breakouts observed in Figures $2-4$, it cannot explain the deeper breakouts.

Before considering the process of breakout growth and extension, we now examine data from the well in Auburn, New York, in order to compare measured values of $\phi_{b}$ and $r_{b}$ with those expected from knowledge of $S_{H}{ }^{*}$ and $S_{h}{ }^{*}$ [Hickman et $a l$., this issue], and the radius $R$ of the drill bit. As we have no knowledge of $\mu$ for the rock in question (the Theresa sandstone of early Paleozoic age), we will estimate a value which reasonably satisfies the breakout data. Table 1 shows the breakout data from five sections in the well from 1471 to 1477 $m$ depth, where the breakout shapes are similar to the theoretical shape discussed above. A hydraulic fracturing stress measurement at a depth of $1480 \mathrm{~m}$ indicates that $S_{H}{ }^{*} / S_{k}{ }^{*}=$ 2.24 , and we have determined empirically that a value of $\mu=0.6$ seems to best satisfy the breakout data.

As shown in Table 1 and Figure 7, as there was apparently little growth after the breakouts initially formed, there is good agreement between the size of the observed breakouts and that of the theoretical prediction. However, the observed breakouts in each case are $1.0-5.0 \mathrm{~mm}$ deeper than those predicted by the theory. This difference is large enough to cause significant problems if we were trying to use the width and depth of the breakouts to estimate $S_{H}{ }^{*} / S_{h}{ }^{*}$. For example, even the breakout at $1471.9 \mathrm{~m}$ (where $\phi_{b}=19^{\circ}$ and $\Delta r_{b}=0.9 \mathrm{~mm}$ ) could not be used to estimate $S_{H}{ }^{*} / S_{h}{ }^{*}$ (Figure 7) because of the steepness of the curves for $\phi_{b} \leq 20^{\circ}$. For small values of $\phi_{b}$ the slightest increase in the observed value of $r_{b} / R$ yields an unreasonably large $S_{H}{ }^{*} / S_{h}{ }^{*}$. In order to use breakout shapes as a method for determining the magnitude of effective principal stresses, it may be necessary to observe breakouts immediately after formation.

In the analysis above, we assumed that the fluid pressure in the well bore was the same as that in the formation $(\Delta P=0)$. Figure 8 illustrates the effect of differences between fluid pressure in the well bore and that in the formation for $S_{H}{ }^{*}=22.0$ $\mathrm{MPa}, S_{h}{ }^{*}=11.0 \mathrm{MPa}$, and $\mu=0.6$. By increasing the well bore pressure by $2.5 \mathrm{MPa}$ (Figure $8 b$ ), the size of the breakouts is substantially diminished for cohesive strengths in the 5-10 $\mathrm{MPa}$ range. However, a decrease in $\Delta P$ by the same amount (Figure 8c) markedly promotes breakout development. In this case, breakouts could occur for rock with a cohesive strength as high as $17.5 \mathrm{MPa}$. The strong influence of $\Delta P$ on the size and shape of breakouts is due to the change in normal stress on potential failure planes near the well bore. Positive $\Delta P$ increases normal streses on those planes and inhibits failure, whereas negative $\Delta P$ lowers normal stresses and promotes failure. A possible practical example of the principle illustrated in Figure 8 is the common practice of using dense additives in drilling muds (like barite) for stabilizing boreholes drilled in poorly indurated (low cohesive strength) formations. The mud increases $\Delta P$, and well bore spalling is minimized.

The simple theory presented above is intended to explain the initial size and shape of breakouts. To address briefly the problem of breakout growth in order to consider the mechanism responsible for some of the deeper breakouts observed in Figures 2-4, we can consider the elastic stress concentration around the well bore once a breakout has formed and the shape of the well bore is no longer circular. The stress field around the now broken-out well bore was computed using the numerical method known as the boundary element technique [Crouch and Starfield, 1983]. Figure 9 shows several successive stages of breakout growth using the same failure criterion used for breakout initiation [after Mastin, 1984]. The applica-
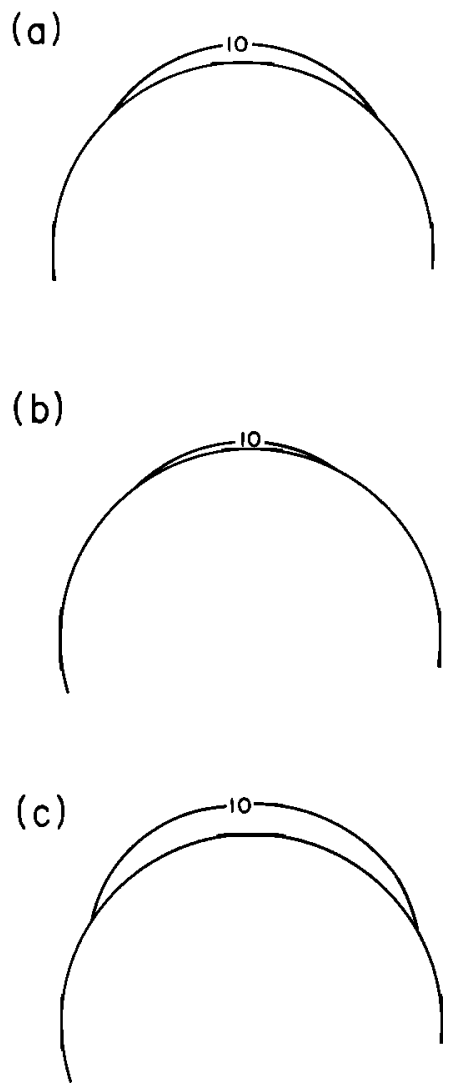

Fig. 8. The effect of excess well bore fluid pressure $\Delta P$ on the size of well bore breakouts. As in Figure 2, the contours define the size of the initial failure zone for $\tau_{0}=10 \mathrm{MPa}$ when $S_{H}{ }^{*}=22.0 \mathrm{MPa}, S_{h}{ }^{*}=$ $11.0 \mathrm{MPa}$, and $\mu=0.6$. (a) No excess well bore pressure $(\Delta P=0)$. (b) Excess pressure in well bore of $2.5 \mathrm{MPa}(\Delta P=2.5 \mathrm{MPa})$. (c) Well bore pressure which is $2.5 \mathrm{MPa}$ less than the formation pore pressure $(\Delta P=-2.5 \mathrm{MPa})$.

bility of the simple elastic failure model to the problem of breakout growth is clearly questionable. There is undoubtedly inelastic deformation occurring as the rock around the well bore fails [e.g., Risnes et al., 1982] and time-dependent effects related to subcritical crack growth are probably occurring [e.g., Martin, 1972]. In fact, Plumb and Hickman [this issue] show apparent evidence of breakout growth with time in the Auburn well. The process of breakout growth is undoubtedly quite complex and the pattern of breakout growth shown in Figure 9 is probably overly simplified. Nevertheless, the calculations with the simple failure model indicate that as the breakouts deepen, they do not become wider. This may explain why breakouts with markedly different depths have approximately the same width (e.g., Figures 2 and 4).

\section{ConClusions}

Observations of well bore breakouts with an ultrasonic borehole televiewer show that regions around well bores fail in a manner which is strongly controlled by the magnitude and orientation of the in situ stress field. Thus study of breakouts in existing wells may prove to be an extremely important new source of data on the orientation of the in situ stress field. A simple elastic failure model seems to confirm the hypothesis that the breakouts form as a compressive failure process, and the theory successfully predicts many of the general characteristics of the observed breakout shapes. However, inelastic deformation around the well bore is apparently quite important 


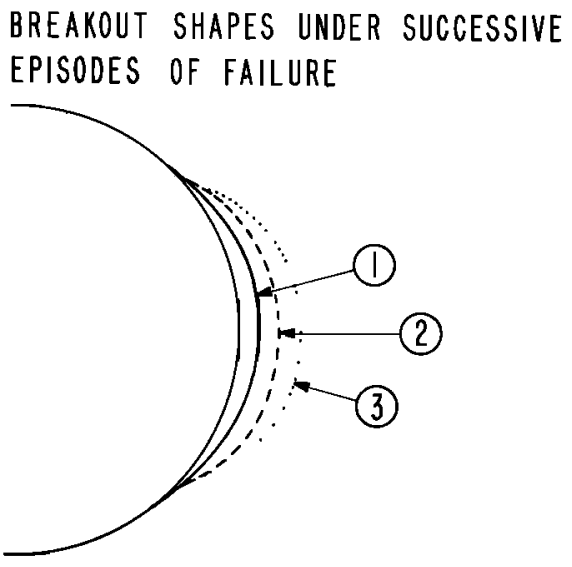

Fig. 9. Successive stages of breakout extension based on boundary element calculations of redistributed stresses around a broken out well bore [after Mastin, 1984].

in arresting breakout growth, and time-dependent failure processes are probably important in breakout evaluation. Both of these processes will have to be considered before breakout growth and development are fully understood.

\section{APPENDIX}

We showed in the body of this paper that it is possible to determine the magnitude of the horizontal principal stresses from measurements of the shape of spalled areas (breakouts) of a well bore, provided that $S_{H}{ }^{*} \leq 3 S_{h}{ }^{*}, \Delta P=0$, and elastic failure theory adequately describes the process. In this appendix we will develop the general solution and show that it is still possible to separate and solve for $S_{H}{ }^{*}$ and $S_{h}{ }^{*}$ as functions of $r_{b}$ and $\theta_{b}$ even when the above conditions are on $S_{H}{ }^{*}$, $S_{h}{ }^{*}$, and $\Delta P$ not explcitly satisfied.

We assume again that the breakout is a zone of compressive shear failure and is bounded by a surface defined by the material's cohesion $\tau_{0}$. Since a single value of $\tau_{0}$ defines the boundary of the breakout, we can parameterize the breakout shape by its maximum depth, $r=r_{b}$ (at $\theta=\pi / 2$ ) and by the azimuth of the point at which the breakout intersects the borehole wall, $\theta=\theta_{b}$ (at $r=R$ ). From (3) we note that $\tau_{r \theta}=0$ whenever $r=R$ or $\theta=\pi / 2$. When $\tau_{r \theta}=0$, (4) becomes

$$
\tau_{0}=\frac{1}{2}\left(1+\mu^{2}\right)^{1 / 2}\left|\left(\sigma_{\theta}-\sigma_{r}\right)\right|-\frac{1}{2} \mu\left(\sigma_{\theta}+\sigma_{r}\right)
$$

If $S_{H}{ }^{*} \leq 3 S_{h}{ }^{*}$ and $\Delta P=0$, then $\sigma_{\theta}>\sigma_{r}$ everywhere in the immediate vicinity of the well, and we do not need to worry about the sign of the stress difference. Equations (6)-(8) were obtained in this manner.

By substituting the complete formulae for the stresses around the borehole (equations (1)-(3)) into (4), we obtain (in place of equations (5)-(7))

$$
\begin{aligned}
\tau_{0}\left(R, \theta_{b}\right) & =\frac{1}{2}\left[\left(a_{1}+a_{2}\right) S_{H}{ }^{*}+\left(b_{1}+b_{2}\right) S_{h}{ }^{*}\right]+e \Delta P \\
\tau_{0}\left(r_{b}, \frac{\pi}{2}\right) & =\frac{1}{2}\left[\left(c_{1}+c_{2}\right) S_{H}{ }^{*}+\left(d_{1}+d_{2}\right) S_{h}{ }^{*}\right]+f \Delta P \\
a_{1} & =-\mu\left(1-2 \cos 2 \theta_{b}\right) \\
a_{2} & = \pm\left(1+\mu^{2}\right)^{1 / 2}\left(1-2 \cos 2 \theta_{b}\right) \\
b_{1} & =-\mu\left(1+2 \cos 2 \theta_{b}\right) \\
b_{2} & = \pm\left(1+\mu^{2}\right)^{1 / 2}\left(1+2 \cos 2 \theta_{b}\right)
\end{aligned}
$$

$$
\begin{aligned}
& c_{1}=-\mu\left(1+2 \frac{R^{2}}{r_{b}^{2}}\right) \\
& c_{2}= \pm\left(1+\mu^{2}\right)^{1 / 2}\left(1-\frac{R^{2}}{r_{b}^{2}}+3 \frac{R^{4}}{r_{b}^{4}}\right) \\
& d_{1}=-\mu\left(1-2 \frac{R^{2}}{r_{b}^{2}}\right) \\
& d_{2}= \pm\left(1+\mu^{2}\right)^{1 / 2}\left(-1+3 \frac{R^{2}}{r_{b}^{2}}-3 \frac{R^{4}}{r_{b}{ }^{4}}\right) \\
& e=\mp\left(1+\mu^{2}\right)^{1 / 2} \\
& f=\mp\left(1+\mu^{2}\right)^{1 / 2} \frac{R^{2}}{r_{b}^{2}}
\end{aligned}
$$

If $\sigma_{\theta}-\sigma_{r}$ is positive, take the positive sign for $a_{2}, b_{2}, c_{2}$, and $d_{2}$ and the negative sign for $e$ and $f$. If $\sigma_{\theta}-\sigma_{r}$ is negative, take the negative sign for $a_{2}, b_{2}, c_{2}$, and $d_{2}$ and the positive sign for $e$ and $f$. Using formulae (9) $-(11)$ become

$$
\begin{gathered}
S_{h}{ }^{*}=2 \frac{\left(a_{1}+a_{2}\right)\left(\tau_{0}+f \Delta P\right)-\left(c_{1}+c_{2}\right)\left(\tau_{0}-e \Delta P\right)}{\left(a_{1}+a_{2}\right)\left(d_{1}+d_{2}\right)-\left(b_{1}+b_{2}\right)\left(c_{1}+c_{2}\right)} \\
S_{H}{ }^{*}=2 \frac{\left(d_{1}+d_{2}\right)\left(\tau_{0}-e \Delta P\right)-\left(b_{1}+b_{2}\right)\left(\tau_{0}-f \Delta P\right)}{\left(a_{1}+a_{2}\right)\left(d_{1}+d_{2}\right)-\left(b_{1}+b_{2}\right)\left(c_{1}+c_{2}\right)} \\
\frac{S_{H}{ }^{*}}{S_{h}{ }^{*}}=\frac{\left(d_{1}+d_{2}\right)\left(\tau_{0}-e \Delta P\right)-\left(b_{1}+b_{2}\right)\left(\tau_{0}-f \Delta P\right)}{\left(a_{1}+a_{2}\right)\left(\tau_{0}-f \Delta P\right)-\left(c_{1}+c_{2}\right)\left(\tau_{0}-e \Delta P\right)}
\end{gathered}
$$

Several features of these equations are immediately apparent. First, if $\sigma_{\theta}-\sigma_{r}$ is positive and $\Delta P=0$, these equations reduce to $(9)-(11)$. As breakouts are caused by well bore spalling due to the high shear stresses near $\theta=\pi / 2$, it turns out that as long as $\tau_{0}$ is reasonably large, the first of these conditions is always satisfied within the breakout zone, even for finite values of $\Delta P$. This is easily demonstrated by noting that $\sigma_{\theta}-\sigma_{r} \gg 0$ at the well bore and that although the difference decreases with radial distance, the material will not fail beyond a region in which this stress difference is still large (and, by inference, positive). Where $\Delta P$ is nonzero, the formation of a breakout at the azimuth of the least effective principal stress still requires that $\sigma_{\theta}-\sigma_{r} \geq 0$. Thus, in solving for the stresses in terms of the parameters describing the breakout shape, we can always assume that this relationship holds.

If $\Delta P$ is nonzero, we cannot solve explicitly for $S_{H}{ }^{*} / S_{h}{ }^{*}$ in a straightforward manner. However, (A7) can still be used to obtain an estimate of the ratio of the stresses if $\tau_{0}-e \Delta P \approx \tau_{0}$ $-k \Delta P$. In all but unusual circumstances (such as overpressured zones), $\Delta P$ will be much smaller than $\tau_{0}$. Also, $e$ and $k$ are approximately equal to one. Therefore, $\tau_{0}-e \Delta P$ will in general be approximately equal to $\tau_{0}-k \Delta P$. Estimates of stress ratio from (11) will therefore be within $10 \%$ or less of the correct value unless the breakout formed when the fluid pressure in the well was greatly different from that in the formation.

Acknowledgments. We would like to thank Andy Ruina for useful discussions during the initial stages of this work and Jack Healy and Steve Hickman for making the televiewer data available. Critical reviews by Joann Stock, James Springer, Richard Plumb, and Sebastian Bell improved the quality of the manuscript.

\section{REFERENCES}

Babcock, E. A., Measurement of subsurface fractures from dipmeter logs, Am. Assoc. Pet. Geol. Bull., 62, 1111-1126, 1978.

Bell, J. S., and D. I. Gough, Northeast-southwest compressive stress 
in Alberta: Evidence from oil wells, Earth Planet. Sci. Lett., 45, 475-482, 1979.

Bell, J. S., and D. I. Gough, The use of borehole breakouts in the study of crustal stress, U.S. Geol. Surv. Open File Rep., 82-1075, $539-557,1982$.

Blumling, P., K. Fuchs, and T. Schneider, Orientation of the stress field from breakouts in a crystalline well in a seismic active area, Phys. Earth Planet. Inter., 33, 250-254, 1983.

Brace, A. B., and D. L. Kohlstedt, Limits on lithospheric stress imposed by laboratory experiments, J. Geophys. Res., 85, 6248-6252, 1980.

Brown, R. O., J. M. Forgotson, and J. M. Forgotson, Jr., Predicting the orientation of hydraulically created fractures in the Cotton Valley Formation of east Texas, paper presented at 55th Annual Meeting, Soc. of Pet. Eng. Dallas, Tex., 1980.

Byerlee, J. D. Friction of rocks, Pure Appl. Geophys., 116, 615-626, 1978.

Cox, J. W., The high resolution dipmeter reveals dip-related borehole and formation characteristics, paper presented at 11th annual Logging Symposium, Soc. of Prof. Well Log. Anal., Los Angeles, Calif., 1970.

Cox, J. W., Long axis onentation in elongated boreholes and its corelation with rock stress data, paper presented at 24th Annual Logging Symposium, Soc. of Prof. Well Log. Anal., Calgary, A1berta, June 27-30, 1983.

Crouch, S. L., and A. M. Starfield, Boundary Element Methods in Solid Mechanics, Allen and Unwin, Boston, 1983.

Gough, D. I., and J. S. Bell, Stress orientations from oil well fractures in Alberta and Texas, Can. J. Earth Sci., 18, 638 645, 1981.

Gough, D. I., and J. S. Bell, Stress orientation from borehole wall fractures with examples from Colorado, east Texas, and northern Canada, Can. J. Earth Sci., 19, 1358-1370, 1982.

Handin, J., Strength and ductility, Mem. Geol. Soc. Am., 97, 223-291, 1966.

Healy, J. H., S. H. Hickman, M. D. Zoback, and W. L. Ellis, Deep borehole stress measurements at the Nevada Test Site, Eos Trans. AGU, 63, 1099, 1982.

Hickman, S. H., J. H. Healy, M. D. Zoback, J. F. Svitek, and J. E. Bretches, In-situ stress, borehole elongation, and natural fracture distribution at depth in central New York State, Eos Trans. AGU, $63,1118,1982$.

Hickman, S. H., J. H. Healy, and M. D. Zoback, In situ stress, natural fracture distribution, and borehole elongation in the Auburn geothermal well, Auburn, New York, J. Geophys. Res., this issue.

Jaeger, J. C., Elasticity, Fracture and Flow, 212 pp., Methuen, London, 1961

Jaeger, J. C., and N. G. W. Cook, Fundamentals of Rock Mechanics, 3rd ed., 593 pp., Chapman and Hall., London, 1979.
Kirsch, G., Die Theorie der Elastizitat und die Beaurforisse der Festigkeitslehre, VDI Z $18571968,42,707$, 1898.

Martin, R. J., Time-dependent crack growth in quartz and its application to the creep of rocks, J. Geophys. Res., 77, 1406-1419, 1972.

Mastin, L. G., An analysis of stress-induced elongation of boreholes at depth, M.S. thesis, Stanford Univ., Stanford, Calif., 1984.

McClintock, F. A., and J. B. Walsh, Friction on Griffith cracks under pressure, Proc. U.S. Natl. Congr. Appl. Mech., 4th, 1015-1021, 1962.

Paterson, M. S., Experimental Rock Deformation: The Brittle Field, 254 pp., Springer-Verlag, New York, 1978

Plumb, R. A., Breakouts in the geothermal well, Auburn, N. Y., Eos Trans. AGU, 63, 1118, 1982.

Plumb, R. A., and S. H. Hickman, Stress-induced borehole elongation: A comparison between the four-arm dipmeter and the borehole televiewer in the Auburn geothermal well, J. Geophys. Res., this issue.

Risnes, R., R. K. Bratli, and P. Horsund, Sand stresses around a wellbore, Soc. Pet. Eng. J., 22, 833-896, 1982.

Schafer, J. N., A practical method of well evaluation and acreage development for the naturally fractured Austin Chalk formation, Log Anal., 2l, 10-23, 1980.

Seeburger, D. A., and M. D. Zoback, The distribution of natural fractures and joints at depths in crystalline rock, $J$. Geophys. Res. $87,5517-5534,1982$.

Springer, J. E., and R. K. Thorpe, Borehole elongation versus in situ stress orientation, paper presented at International Conference on in Situ Testing of Rock and Soil Masses, Univ. of Calif., Santa Barbara, Jan. 4-8, 1981.

Stock, J., J. Healy, and J. Svitek, The orientation of the current stress field on Yucca Mountain, Nevada, as determined from televiewer logs, Eos Trans. $A G U, 64,319,1983$.

Zemanek, J., E. E. Glen, Jr., L. J. Norton, and R. L. Cardwell, Formation evaluation by inspection with the borehole televiewer, Geophysics, 35, 254-269, 1970.

R. N. Anderson and D. Moos, Lamont-Doherty Geological Observatory of Columbia University, Palisades, NY 10964.

L. Mastin, U.S. Geological Survey, 345 Middlefield Road, Menlo Park, CA 94025.

M. D. Zoback, Department of Geophysics, Stanford University, Stanford, CA 94305.

(Received February 1, 1984;

revised August 2, 1984;

accepted October 15, 1984.) 